Article

\title{
A Comparative Study on Energy and Exergy Analyses of a CI Engine Performed with Different Multiple Injection Strategies at Part Load: Effect of Injection Pressure
}

\author{
Muammer Özkan \\ IC Engines Laboratory, Department of Mechanical Engineering, Y1ld1z Technical University, \\ Istanbul 34349, Turkey; E-Mail: muaozkan@yildiz.edu.tr; Tel.: +90-212-383-28-34 (ext. 2834); \\ Fax: +90-212-261-66-59
}

Academic Editor: Marc A. Rosen

Received: 23 October 2014 / Accepted: 7 January 2015 / Published: 12 January 2015

\begin{abstract}
In this study, a four stroke four cylinder direct injection CI engine was run using three different injection pressures. In all measurements, the fuel quantity per cycle, the pre injection and main injection timing, the boost pressure and the engine speed were kept constant. The motor tests were performed under 130, 140 and $150 \mathrm{MPa}$ rail pressure. During the theoretical part of the study, combustion, emission, energy and exergy analysis were made using the test results. An increase in the injection pressure increases combustion efficiency. The results show that combustion efficiency is not enough by itself, because the increase in the power need of the injection pump, decreases the thermal efficiency. The increase in the combustion temperature, increases the cooling loss and decreases the exergetic efficiency. In addition, the $\mathrm{NO}_{\mathrm{x}}$ emissions increased by $12 \%$ and soot emissions decreased $44 \%$ via increasing injection pressure by $17 \%$. The thermal and exergetic efficiencies are found inversely proportional with injection pressure. Exergy destruction is found independent of the injection pressure and its value is obtained as $\sim 6 \%$.
\end{abstract}

Keywords: second-law; internal combustion engines; multiply injection; exergy; energy; exhaust emissions 


\section{Introduction}

Marc A. Rosen introduced and exemplified a methodology describing the relationship between the use of exergy and energy research findings to use the resources more efficiently [1]. Exergy is defined as the maximum theoretical work that can be obtained from a system as it comes to equilibrium with a reference environment. Energy, entropy and exergy are applied in all scientific and engineering fields. Production of entropy is one of the obstacles to overcome in order to optimize the process and performance [2-4].

In internal combustion engines (ICE) exergy applications are significant. Internal combustion engines are widely used in the marine and land vehicles as well as land based power stations. All of these engines were subjects of exergy analysis.

Acikkalp et al. did exergy analysis on a tri-generation system, which used dual fuel engine, found that a turbo air compressor was the most important element from the thermodynamic perspective [5]. Santo computed energy and exergy efficiency of a tri-generation system with ICE engine under two different performance strategies. He concluded that the exergy efficiency was 35\%-38.4\% and the utilization factor was within the range of $65 \%-81 \%$ [6]. Ehyaie et al. studied the exergy, economics and environmental analysis of a residential building. They determined the proper engine set for power and heating of the building [7]. Chintala et al. analyzed the exergy of a dual fuel diesel engine in which $\mathrm{H}_{2}$ was added in intake air for lower entropy generation. The irreversibility of the unburned fuel was reduced at higher temperatures yet $\mathrm{H}_{2}$ did not have an impact on mixture and friction irreversibility [8].

López et al. performed exergy analysis in an engine using a mixture of olive-pomace oil biodiesel/diesel. The use of biodiesel instead of diesel decreased the maximum power by $5.6 \%$ and increased the fuel consumption up to $7 \%$. Nevertheless there were no significant differences between results which obtained from engine test performed with biodiesel/diesel based on thermodynamics second law analysis [9]. Azoumah et al. optimized the CI engine performance by utilizing the exergy analysis for diesel and diesel-biodiesel fuel. They concluded that the combination of exergy and gas emission analyses were highly effective in evaluating engine load [10]. Caliskan et al. studied the effects of different ambient temperatures on exergy on a CI engine using high-oleic methyl ester fuel. The results showed that the exergetic efficiency decreased with the dead-state temperature [11].

Nieminen et al. developed an exergy model for a natural aspirated gasoline and hydrogen engine according to the second law of thermodynamics. They determined that the larger part of the chemical exergy was transformed into work exergy and the second law efficiency was higher for Hydrogen powered engine, in comparison to those of gasoline powered engine, due to the lower fuel consumption and irreversibility of hydrogen engine [12]. Waller et al. computed current and theoretical maximum exergy efficiency for the use of compressed natural gas (CNG) in ICE, a source of hydrogen for a fuel cell for electric vehicle (FCEV) and generate electricity for a battery electric vehicle BEV. The highest current exergy efficiencies for CNG, FCEV and BEV were 31\%, 25\% and 44\% respectively, and the highest theoretical exergy efficiency for $\mathrm{CNG}$, FCEV and BEV were 63\%, 87\% and 84\% [13]. Jafarmadar analyzed the exergy of a diesel-hydrogen dual fuel engine modeled by using the Extend Cohoren Flame Model-Three Zone Model. The results show that an increase in the gas fuel to air ratio from 0.3 to 0.8 causes a decrease of the exergy efficiency from $43.7 \%$ to $34.5 \%$ as well as a decrease of irreversibility from $29.8 \%$ to $26.6 \%$. By employing the three zone model in another study he carried out exergy analyses for four different exhaust gas recirculation (EGR). He concluded that the exergy 
efficiency at $0 \%, 10 \%, 20 \%$ and $30 \%$ EGR mass fraction values, and $50 \%$ of the work load fell from $31.74 \%$ to $25.38 \%$. In his study with a three dimensional model of a CI engine with a front and a main combustion chamber, he concluded a correlation of the total irreversibility to the combustion in the main chamber. Under partial load, $56 \%$ of the total irreversibility and under full load $77 \%$ of total irreversibility were related to the combustion in the main chamber [14-16]. Saxena et al. investigated the exergy losses and their changes under different conditions by using multi regional chemical kinetics model in a gasoline fuelled HCCI engine. The in cylinder loss mechanism was defined with components such as combustion loss, heat loss, unburned particles, physical exergy loss and exhaust loss. First a combustion timing was set for optimal efficiency then the changes in the components of the loss mechanism were studied for early and late combustion condition. The results suggest that the equivalence ratio should be maintained at relatively high values across most operating conditions while intake pressure is used to vary engine load [17]. Sezer et al. examined the effects of the SI engine's charge properties on the exergy equilibrium. They found that the increasing of fuel-air equivalence ratio rose the irreversibility and hence led to the exergy loss .Slightly lean mixture ratios yielded the best First and Second Law efficiencies [18]. Fu et al. studied gasoline engine at low speed and low load conditions and detected significant temperature losses due to cooling water. Under high speed and high load conditions exhaust gas energy is more than the cooling water energy in terms of quantity, energy percentage and exergy efficiency [19]. Ghazikhani et al. aimed at reducing the brake specific fuel consumption (bsfc) by utilizing the exhaust gas exergy. They inserted a reverse flow double piped heat exchanger into the engine exhaust line and operated the engine at different load and speed. The recovered exergy energy increased with the increased engine load and speed. The results showed that bfsc could be reduced approximately $10 \%$ by utilizing recovered exergy [20]. Nemati et al. investigated the effects of the spraying time of a hydrogen fueled direct spraying SI engine from exergy and energy perspectives. They determined that combustion and exhaust irreversibility was highly affected by the changes of equivalence ratio, and with the rising equivalence ratio the amount of fuel availability transferred from exhaust into environment increased. In the cases of late and early spraying, equivalence ratio changes had different effects on accumulated work availability [21]. Zheng et al. studied low temperature combustion to decrease the $\mathrm{NO}_{\mathrm{x}}$ and particle matter (PM) by means of high EGR and late injection in accordance with the Second Law of Thermodynamics. At conventional injection timing and $0 \%$ EGR, 30\% of fuel exergy was destructed during the combustion process. At 45\% EGR level, the destructed exergy fell down to $20 \%$ of fuel exergy. At all classical/conventional and late sprayings transferred exergy percentage increased with rising EGR [22]. Costa et al. investigated energetic and exergetic analyses of a $188 \mathrm{~kW}$ diesel engine when it was operated with diesel and natural gas. For the powers exceeding $80 \mathrm{~kW}$ the dual fuel modes' exergetic efficiency is calculated higher than the pure diesel mode. The total exergy, exergy destruction and waste heat exergy was found higher for dual fuel mode up to $50 \mathrm{~kW}$ engine power and for the engine power exceeding $50 \mathrm{~kW}$ the total exergy, exergy destruction and waste heat exergy is higher for pure diesel mode for all conditions. The exergy of combustion products was found higher for dual fuel mode up to $80 \mathrm{~kW}$ engine power, and for the engine power exceeding $80 \mathrm{~kW}$ it was found that exergy of combustion products was higher for pure diesel mode [23].

Multiple injection strategies are widely used in CI engines to reduce $\mathrm{NO}_{\mathrm{x}}$ emission [17]. Therefore, effect of working parameters of multiple injection strategies such as dwell time, main and pre injection 
timing, mass proportion and injection pressure on exergy has created a new research field. Karra et al. performed experiments using a 4-cylinder $4.5 \mathrm{~L}$ engine. They made experiments at $-20{ }^{\circ} \mathrm{CA}$ (ATDC) and $5{ }^{\circ} \mathrm{CA}$ (ATDC) main injection and $-40{ }^{\circ} \mathrm{CA},-15{ }^{\circ} \mathrm{CA}$ (ATDC) with pilot injection timings at different injection pressures for $15 \%, 25 \%, 40 \%$ pilot injection strategies. The increase of injection pressures $100 \mathrm{MPa}$ to $150 \mathrm{MPa}$ and $200 \mathrm{MPa}$ increased the $\mathrm{NO}_{\mathrm{x}}$ emissions, and decreased the soot emissions, which was explained by the better the atomization, more rapid premixed burn and higher local temperatures increase $\mathrm{NO}_{\mathrm{x}}$ emission and also they explained decrease of soot emissions with more complete combustion [24]. Ozkan et al. analyzed the combustion, energy, and exergy of a multiple injection CI engine at three different alternative injection strategies despite their differences in injection pressure. The results show that the increasing injection pressure increased the combustion efficiency yet decreased the effective work hence indicating a need for optimization [25].

There are studies in the literature that show the effects of ambient conditions and usage of different fuels in CI in terms of thermal and exergetic efficiencies. In this study, multiple injection strategies which are performed under different injection pressures are compared in terms of thermal and exergetic efficiencies. This study also examined how the results could be used to decrease $\mathrm{NO}_{\mathrm{x}}$ emissions and how the exergy would be affected.

\section{Analysis}

\subsection{Second Law Analysis}

In diesel engines, the cylinder is charged up with an intake air, which it was cooled by an intercooler after its pressure was increased by a turbocharger. Then the fuel is injected on to this intake air at the last period of compression stroke. In diesel engines the control volume is defined as combustion chamber volume. In order to make an exergy analysis, the thermodynamic and thermo mechanic exergies of intake air and fuel which enters the combustion chamber has to be calculated. The inlet conditions of intake air to the combustion chamber is identified by turbocharger system which uses exhaust energy hence fuel exergy and the intercooler which it is assembled between engine and turbocharger.

In this research, the energy that was used for compressing the inlet air was taken into account with considering the turbocharger outlet conditions as exhaust gas conditions. The inlet air temperature at the inlet of turbocharger is nearly equal to dead state temperature so thermo mechanic exergy of inlet air was accepted as zero. There is a similar situation for the fuel thermo-mechanical exergy as it is stated for intake air. The fuels' temperature is equal to the ambient temperature at the inlet of the engine fuel system therefore the thermo-mechanic exergy of fuel is accepted as zero. The chemical exergy of fuel is calculated from the literature. The exhaust, cooling, inter-cooling, uncounted heat losses and their exergies are calculated from the measurements.

The operational conditions of the engines can be evaluated using the exergy calculations.

The Equation (1) was used to calculate the thermal efficiency of the engine [26];

$$
\eta_{\mathrm{t}}=\frac{\dot{\mathrm{W}}}{\dot{\mathrm{Q}}_{\mathrm{f}}}=\frac{\dot{\mathrm{W}}}{\dot{\mathrm{m}} \times \mathrm{LHV}}
$$


The Equations (2)-(5) were used to calculate the exergy, specific exergy, thermo-mechanical and chemical exergies of fuel respectively.

$$
\begin{aligned}
& E x_{f}=\dot{m}_{f} \times e_{f} \\
& e_{f}=e_{f}^{t h}+e_{f}^{c h}
\end{aligned}
$$

Using Equations (4) and (5), the thermo mechanical and chemical exergies of the fuel were calculated, respectively.

$$
\begin{gathered}
\mathrm{e}_{\mathrm{f}}^{\text {th }}=\left(\mathrm{h}-\mathrm{h}_{0}\right)-\mathrm{T}_{0} \times\left(\mathrm{s}-\mathrm{s}_{0}\right) \\
\mathrm{e}_{\mathrm{f}}^{\text {th }}=0 \\
\mathrm{e}_{\mathrm{f}}^{\mathrm{ch}}=\left[1.0401+0.1728 \frac{\mathrm{h}}{\mathrm{c}}+0.0432 \frac{\mathrm{o}}{\mathrm{c}}+0.2169 \frac{\mathrm{s}}{\mathrm{c}}\left(1-2.0628 \frac{\mathrm{h}}{\mathrm{c}}\right)\right] \times \mathrm{LHV}
\end{gathered}
$$

The reason of thermo mechanical and chemical exergies being nearly equal to zero is the closeness of the combustion air entering the control volume and the reference state. The control volume is defined as the volume of combustion chamber of test engine in this study. Therefore, the thermo mechanical exergy of the fuel is also zero.

The specific chemical exergies per unit mass of liquid fuels can be evaluated using the following expression [27]. The mass fractions of carbon, hydrogen, oxygen and sulfur are shown as $\mathrm{C}, \mathrm{H}, \mathrm{O}$ and $\mathrm{S}$ respectively. The reaction Equation of diesel fuel (No: 2) can be written as follows:

$$
\begin{aligned}
& \mathrm{C}_{14.09} \mathrm{H}_{24.78}+35.264\left(\mathrm{O}_{2}+3.76 \mathrm{~N}_{2}\right) \rightarrow 14.929 \mathrm{O}_{2}+0.017 \mathrm{CO}+14.04 \mathrm{CO}_{2}+ \\
& 0.00236 \mathrm{C}_{14.09} \mathrm{H}_{24.78}+0.4911 \mathrm{NO}+0.0161 \mathrm{NO}_{2}+132.343 \mathrm{~N}_{2}+12.363 \mathrm{H}_{2} \mathrm{O}
\end{aligned}
$$

The exhaust loss was calculated using Equation (6):

$$
\dot{\mathrm{Q}}_{\mathrm{exh}}=\sum_{\mathrm{i}=1}^{\mathrm{n}} \mathrm{n}_{\mathrm{i}} \overline{\mathrm{c}}_{\mathrm{pi}}\left(\mathrm{T}_{\mathrm{exh}}-\mathrm{T}_{0}\right) \text {. }
$$

The specific heat of the exhaust was calculated by using Equation (7).

$$
\bar{c}_{p}=a+b T+c T^{2}+d T^{3}
$$

The coefficients a, b, c, and d for each exhaust gas are taken from the literature [26]. The exhaust exergy and specific molar exhaust exergy were calculated using Equations (8) and (9).

$$
\begin{aligned}
& \dot{\mathrm{Ex}}_{\mathrm{exh}}=\mathrm{n} \times \overline{\mathrm{e}}_{\mathrm{exh}} \\
& \overline{\mathrm{e}}_{\mathrm{exh}}=\overline{\mathrm{e}}^{\mathrm{th}}+\overline{\mathrm{e}}^{\mathrm{ch}}
\end{aligned}
$$

The thermo mechanical and chemical exergies of the exhaust gases were calculated using Equations (10) and (11), respectively:

$$
\begin{gathered}
\overline{\mathrm{e}}^{\mathrm{th}}=\sum_{\mathrm{i}=1}^{\mathrm{n}} \mathrm{a}_{\mathrm{i}}\left[\left(\overline{\mathrm{h}}_{\mathrm{i}}-\overline{\mathrm{h}}_{\mathrm{i} 0}\right)-\mathrm{T}_{0}\left(\left(\overline{\mathrm{s}}_{\mathrm{i}}-\overline{\mathrm{s}}_{\mathrm{i} 0}\right)-\mathrm{R}_{\mathrm{u}} \ln \frac{\mathrm{p}}{\mathrm{p}_{0}}\right)\right], \\
\overline{\mathrm{e}}^{\mathrm{ch}}=\mathrm{R}_{\mathrm{u}} \mathrm{T}_{0} \sum_{\mathrm{i}=1}^{\mathrm{n}} \mathrm{a}_{\mathrm{i}} \ln \left(\frac{\mathrm{y}_{\mathrm{i}}}{\mathrm{y}_{\mathrm{i}}^{\mathrm{e}}}\right),
\end{gathered}
$$

where $a_{i}$ is the molar amount of component $i$; where $y_{i}$ is the molar ratio of the $i$-th component in the exhaust gas and $\mathrm{y}_{\mathrm{i}}^{\mathrm{e}}$ is the molar ratio of the $\mathrm{i}$-th component in the reference environment [28]. 
The heat loss from the cooling water is calculated using Equation (12).

$$
\dot{\mathrm{Q}}_{\mathrm{cw}}=\dot{\mathrm{m}}_{\mathrm{cw}} \mathrm{c}_{\mathrm{p}, \mathrm{cw}}\left(\mathrm{T}_{\mathrm{cw}, \mathrm{in}}-\mathrm{T}_{\mathrm{cw}, \mathrm{out}}\right)
$$

Heat is an irregular form of energy, and it is only possible to convert a slight portion of the heat into work. The part of heat that can be turned into work is a regular form of wasted energy. Heat transmission is always accompanied by an exergy transmission [26]. The cooling water exergy was calculated by using Equation (13).

$$
\dot{\mathrm{Ex}}_{\mathrm{cw}}=\left(1-\frac{\mathrm{T}_{0}}{\mathrm{~T}_{\mathrm{cw}, \mathrm{in}}}\right) \dot{\mathrm{Q}}_{\mathrm{cw}}
$$

The intercooler heat loss and exergy were calculated using Equations (14) and (15) respectively.

$$
\begin{gathered}
\dot{\mathrm{Ex}}_{\mathrm{cw}}=\left(1-\frac{\mathrm{T}_{0}}{\mathrm{~T}_{\mathrm{cw}, \mathrm{in}}}\right) \dot{\mathrm{Q}}_{\mathrm{cw}} \\
\dot{\mathrm{Ex}}_{\mathrm{ic}}=\left(1-\frac{\mathrm{T}_{0}}{\mathrm{~T}_{\mathrm{ic}, \mathrm{in}}}\right) \dot{\mathrm{Q}}_{\mathrm{ic}}
\end{gathered}
$$

The engine block heat loss was calculated by using Equation (16) and exergy was calculated by using Equation (17).

$$
\begin{gathered}
\dot{\mathrm{Q}}_{\mathrm{eb}}=\dot{\mathrm{m}}_{\mathrm{f}} \mathrm{LHV}-\dot{\mathrm{W}}_{\mathrm{eff}}-\dot{\mathrm{Q}}_{\mathrm{exh}}-\dot{\mathrm{Q}}_{\mathrm{cw}}-\dot{\mathrm{Q}}_{\mathrm{ic}}-\dot{\mathrm{Q}}_{\mathrm{u}} \\
\dot{\mathrm{Ex}}_{\mathrm{eb}}=\left(1-\frac{\mathrm{T}_{0}}{\mathrm{~T}_{\mathrm{s}}}\right) \dot{\mathrm{Q}}_{\mathrm{eb}}
\end{gathered}
$$

Hence, entropy production always causes exergy destruction [26]. The exergy destruction fuel was calculated by using Equation (18).

$$
\dot{E x_{d e s t}}=\dot{E x_{f}}-\dot{W}_{\text {eff }}-\dot{E x_{e x h}}-\dot{E x_{c w}}-\dot{E x_{i c}}-\dot{E x_{u}}
$$

$\dot{E x_{\text {dest }}}$ represents the rate of exergy destroyed in the control volume due to irreversibilities. The exergetic efficiency was calculated by using Equation (19):

$$
\varepsilon=\frac{\mathrm{W}_{\mathrm{eff}}}{\mathrm{Ex}_{\mathrm{f}}}
$$

\subsection{Combustion Analysis}

Different fuel injection strategies were used in investigating the operating parameters of the engine. AVL BOOST (AVL, Graz, Austria) software was used to validate the experiment, for a better understanding of the results. The combustion model and modeling methodology in AVL Boost software described in references Chmela 1998 and 1999 was developed by Chmela [29,30]. AVL BOOST is an advanced and fully integrated "Virtual Engine Simulation Tool" for accurately predicting engine performance. For 1D thermodynamic modeling of an internal combustion engine in BOOST simulation environment; the intake and exhaust system geometries, the volumes of all plenums; the properties of the boost system, the engine combustion chamber geometry, the valve timing diagrams and also the injection system properties, injection rate profile, injection pressure and blow by for the specified engine operating condition, the combustion model and wall temperature 
gradients and heat transfer model should be provided for analyzing of heat release rate and in cylinder pressure. In this research, the $1 \mathrm{D}$ engine model of the test engine which was validated for a wide range of engine operating conditions via comparing the measured and simulated in cylinder pressure data, was used for analyze [31].

The Mixed Controlled Combustion Model (MCC) in AVL Boost software was used for the RoHR analysis. The model basically considers the effects of the premixed combustion (PMC) and diffusion-MCC controlled combustion processes according to Equation (20).

$$
\frac{\mathrm{dQ}_{\text {total }}}{\mathrm{d} \alpha}=\frac{\mathrm{dQ}_{\mathrm{MCC}}}{\mathrm{d} \alpha}+\frac{\mathrm{dQ}_{\mathrm{PMC}}}{\mathrm{d} \alpha}
$$

The released energy for mixing controlled phase was calculated with Equation (21).

$$
\frac{d Q_{M C C}}{d \alpha}=C_{\text {comb. }} f_{1}\left(m_{f}, Q_{M C C}\right) \cdot f_{2}(k, V)
$$

A Vibe function is used to describe actual heat release premixed phase which it was given at Equations (22) and (23).

$$
\begin{gathered}
\frac{\frac{d Q_{P M C}}{Q_{P M C}}}{d \alpha}=\frac{a}{\Delta \alpha_{c}} \cdot(m+1) \cdot y^{m} \cdot e^{-a \cdot y^{(m+1)}} \\
y=\frac{\alpha-\alpha_{i d}}{\Delta \alpha_{c}}
\end{gathered}
$$

\section{Experimental Section}

Ford Lynx TDCI CI engine and diesel fuel according to EN590 fuel standard were used in the study. Technical specifications of the test engine and test fuel were given in Tables 1 and 2 respectively.

Table 1. Technical specifications of the engine used in test.

\begin{tabular}{|l|c|}
\hline Engine type & $1.8 \mathrm{~L} \mathrm{Lynx} \mathrm{TDCi}$ \\
\hline Total displacement & $1753 \mathrm{~cm}^{3}$ \\
\hline Number of cylinders & 4 \\
\hline Stroke & $82 \mathrm{~mm}$ \\
\hline Bore & $82.5 \mathrm{~mm}$ \\
\hline Compression ratio & $17: 1$ \\
\hline Max. torque (at 2000 rpm) & $239.7 \mathrm{Nm}$ \\
\hline Max. power (at 4000 rpm) & $66 \mathrm{~kW}$ \\
\hline Fuel injection pomp & 4 M5Q-9B395-AD \\
\hline Injectors & M5Q-9F593-AD \\
\hline Turbocharger & Garrett GT17 VGT \\
\hline
\end{tabular}


Table 2. Properties of the fuel used in test and test methods of fuel.

\begin{tabular}{cccc}
\hline Properties & Unit & Value & Test method \\
\hline Cetan number & - & 52 & D613 \\
Density & $@ 15^{\circ} \mathrm{C}, \mathrm{g} / \mathrm{ml}$ & 0.8358 & $\mathrm{D} 4052$ \\
Viscosity & $@ 40{ }^{\circ} \mathrm{C}, \mathrm{mm}^{2} / \mathrm{s}$ & 2.79 & $\mathrm{D} 445$ \\
Cold point & ${ }^{\circ} \mathrm{C}$ & -17 & $\mathrm{D} 2500$ \\
Water content & $\mathrm{mg} / \mathrm{kg}$ & 110 & $\mathrm{IP} 438$ \\
Ash content & $\%, \mathrm{~m} / \mathrm{m}$ & 0.001 & $\mathrm{D} 482$ \\
LHV & $\mathrm{MJ} / \mathrm{kg}$ & 42.58 & $\mathrm{IP} 12$ \\
\hline
\end{tabular}

A $220 \mathrm{~kW}$ AVL APA 204/8 dynamometer, AVL 735 C fuel mass flow meter, AVL 735 S fuel temperature measurement unit, ABB SensyFlow-P mass air flow meter, Horiba MEXA 7100 DEGR gases analyzer, AVL $415 \mathrm{~S}$ smoke meter were used in the motor tests. Puma Open 1.4 ISAC400 test automation system was used to run the tests. The technical properties of the test apparatus are given in Tables 1-3. A schematic shape of the test devices is presented in Figure 1. During the engine tests, ambient conditions such as temperature, pressure and relative humidity were kept constant.

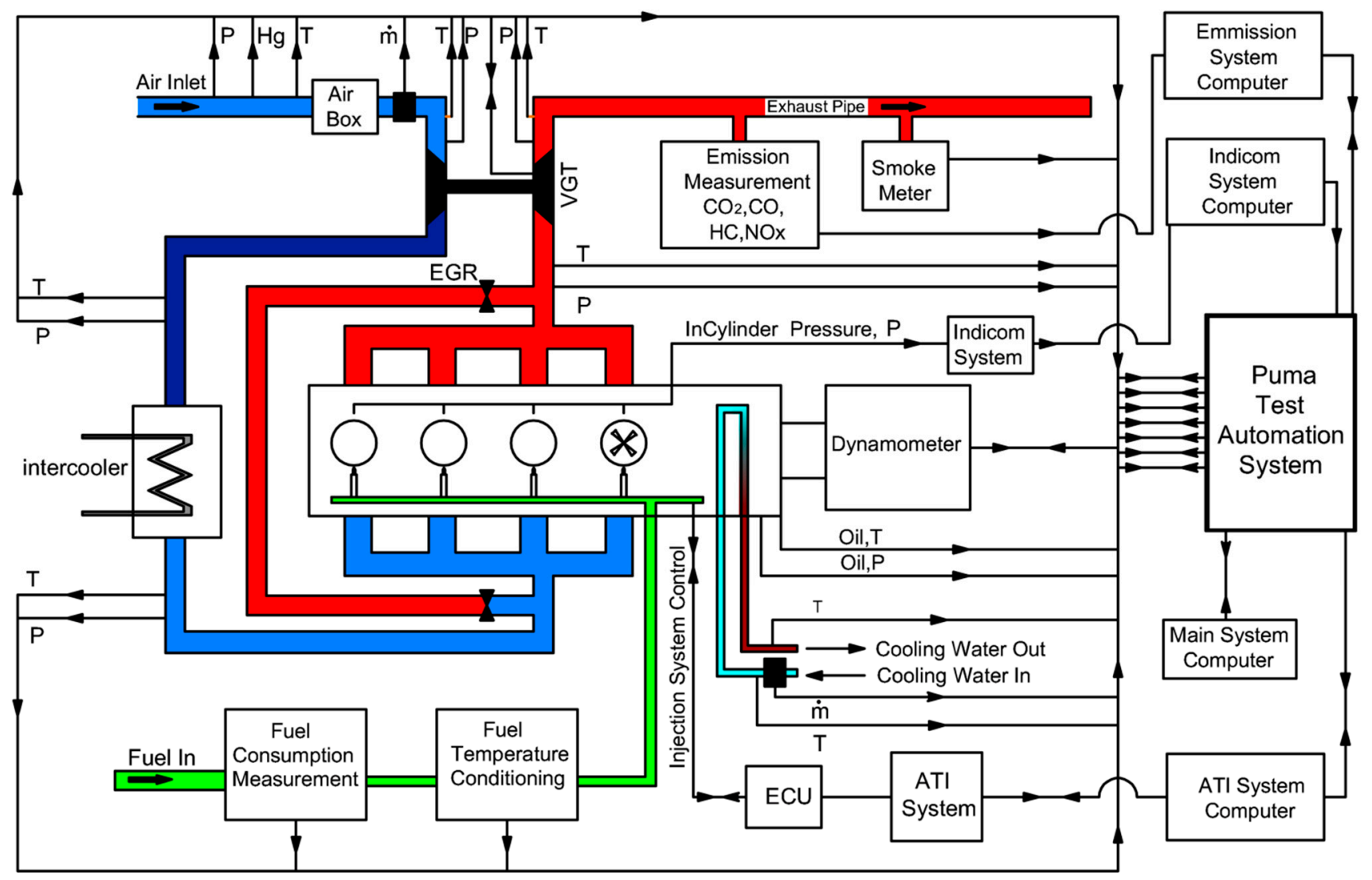

Figure 1. Experimental set-up. 
Table 3. Technical specifications of the measurement devices used in test.

\begin{tabular}{|l|c|c|}
\hline Dynamometer & AVL APA 204/ 8 & $0.1 \%$ Full scale. Torque, $\pm 1 \mathrm{rpm}$ \\
\hline Fuel mass flow measurement & AVL 735S & $\pm 0.5 \mathrm{~kg} / \mathrm{m}^{3}$ \\
\hline Fuel temperature controller & AVL 753C & - \\
\hline Smoke meter & AVL 415S & - \\
\hline Blow by & AVL 442 & $1.5 \%$ Full scale \\
\hline Gas analyzer & Horiba MEXA 7100 DEGR & - \\
\hline- & THC & FID \\
\hline- & $\mathrm{NO}_{\text {or NO }}$ & CLD \\
\hline- & $\mathrm{CO}_{2}$ and CO & IRD \\
\hline- & $\mathrm{O}_{2}$ & PMD \\
\hline Combustion chamber indicating system & AVL IndiSet Advanced Plus & - \\
\hline Pressure transducer & AVL GH13P & - \\
\hline Air flow measurement & ABB Sensy Flow P-2400 & - \\
\hline Coolant flow measurement & Krohne optiflux 5010C & - \\
\hline
\end{tabular}

Before the engine tests, the test matrixes that include quantity of main and pre-injection fuel, main and pre-injection timing, engine speed, boost and rail pressure data were created. This data was uploaded on the test automation system. The automation system, engine control unit (ECU) and test hardware, running at specified conditions and collect data matrices and were reported. The engine speed, total fuel mass injected per cycle, main and pre-injection timings and intake manifold pressure were kept constant. The engine test performed at $0 \%$ EGR condition because of eliminate EGR effect on combustion, engine performance and emissions. The injection pressure was changed from $130 \mathrm{MPa}$ to $150 \mathrm{MPa}$.

Combustion analyses, the thermal and exergetic efficiencies, the cooling loss and exergy, the exhaust loss and exergy, the inter-cooling loss and exergy, and the engine block heat loss and exergy, were calculated using experimental results. The heat release rate and combustion temperature were calculated using the AVL Boost software package.

Description of test modes and the performance data of test points are given in Tables 4 and 5, respectively. While the injection strategy is indicated in Figure 2, 6\% of total injected fuel was injected as pilot injection at $15{ }^{\circ} \mathrm{CA}$ before top dead center and the $94 \%$ of total injected fuel was injected at $5{ }^{\circ} \mathrm{CA}$ before top dead center as main injection in Modes 1-3. The injection pressure was kept as 130, 140 and $150 \mathrm{MPa}$ respectively for Mode 1 , Mode 2 and Mode 3.

Table 4. Description of modes used in test.

\begin{tabular}{|c|c|c|c|c|c|c|}
\hline & \multirow{2}{*}{$\begin{array}{l}\text { Total Injected } \\
\text { Fuel Quantity }\end{array}$} & \multicolumn{2}{|c|}{ Injection Quantity } & \multicolumn{3}{|c|}{ Injection Timing } \\
\hline & & Pre & Main & Pre & Main & Rail Pressure \\
\hline & $\mathrm{mg} /$ stroke & TIFQ \% & TIFQ \% & $\mathrm{BTDC}\left(\mathrm{CA}^{\circ}\right)$ & $\operatorname{Main}\left(\mathrm{CA}^{\circ}\right)$ & $\mathrm{MPa}$ \\
\hline MODE1 & 28 & 6 & 94 & 15 & 5 & 130 \\
\hline MODE2 & 28 & 6 & 94 & 15 & 5 & 140 \\
\hline MODE3 & 28 & 6 & 94 & 15 & 5 & 150 \\
\hline
\end{tabular}


Table 5. Performance data observed from engine test.

\begin{tabular}{ccccc}
\hline & Engine Speed & Brake Torque & Brake Power & BSFC \\
\cline { 2 - 5 } & $\mathrm{rpm}$ & $\mathrm{Nm}$ & $\mathrm{kW}$ & $\mathrm{g} / \mathrm{kWh}$ \\
\hline MODE1 & 2500 & 131.7 & 34.48 & 234.93 \\
MODE2 & 2500 & 131.2 & 34.34 & 235.82 \\
MODE3 & 2500 & 130.3 & 34.11 & 237.45 \\
\hline
\end{tabular}

\section{Results and Discussion}

The rate of heat release, in-cylinder temperature and in-cylinder pressure that was obtained from the thermodynamic model of test engine created in AVL-Boost software is represented in Figures 2-4. The simulation results showed that the indicated work is increased with the increase of injection pressure. In addition, the indicated work values obtained from simulation for Modes 1-3 are 144.6 Nm, 146.1 Nm and $147.8 \mathrm{Nm}$, respectively. Although the indicated work is increased, the main reason of the decrease in effective work is the increase of high pressure pump work with increase of injection pressure. Figure 2 presents the effects of injection pressure on RoHR. The increase of injection pressure decreases the droplet size of diesel spray and shortens the duration of fuel combustion. The increase of fuel pressure increased the gradient of RoHR at pilot and main injection phases. In addition, the decrease in the RoHR near TDC reduces the in-cylinder temperature as shown in Figure 3.

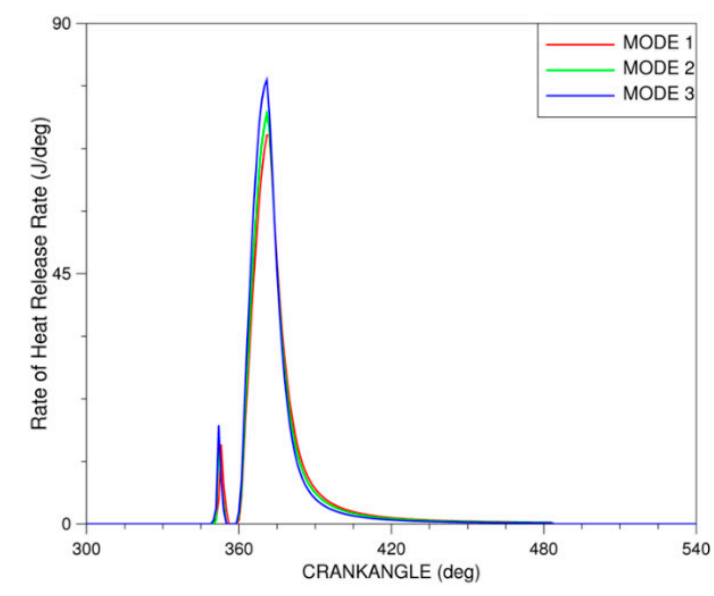

Figure 2. Variation of rate of heat release for the modes.

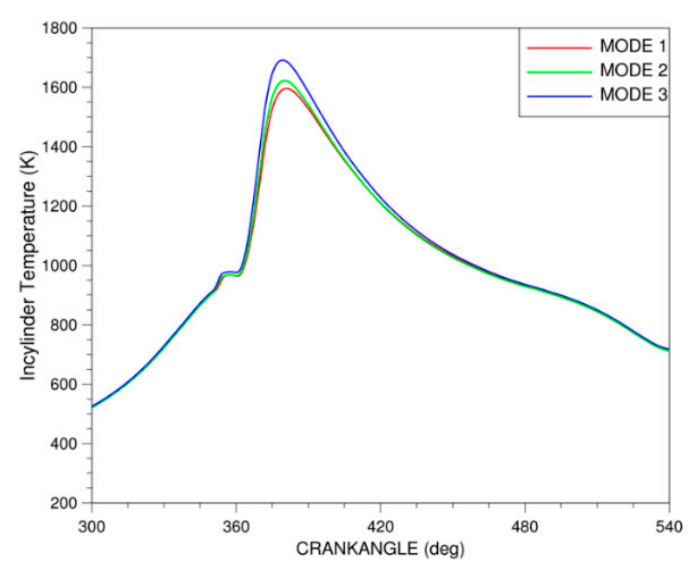

Figure 3. Variation of in-cylinder temperature for the modes. 


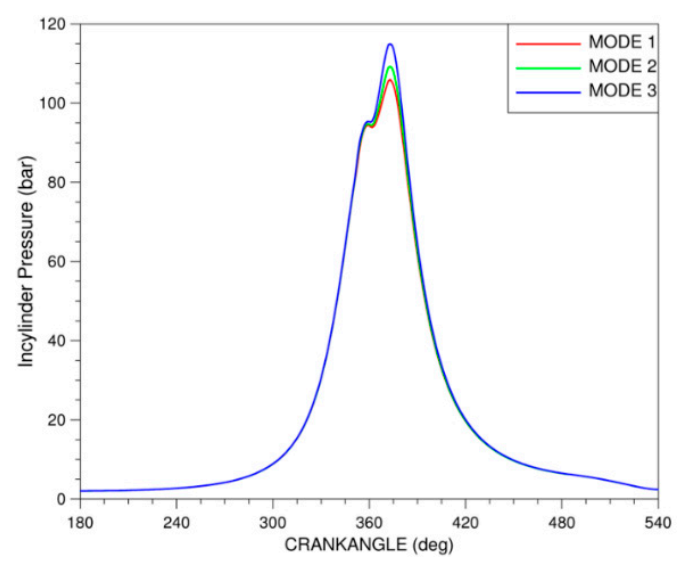

Figure 4. Variation of in-cylinder pressure according to the modes.

Figure 3 reveals that the implementation of increase of injection pressure increases the in-cylinder temperature. Similar to the in-cylinder temperature, maximum in cylinder pressure increased with the increase of injection pressure. The increase of injection pressure resulted as the increase of $\mathrm{dp} / \mathrm{d} \alpha$ and $\mathrm{dT} / \mathrm{d} \alpha$ (Figures 3 and 4).

The experimental results demonstrate that the increase in injection pressure increases the $\mathrm{NO}_{\mathrm{x}}$ concentration, and decreases the soot concentration (Figure 5). This result is harmonious with the reference [24].

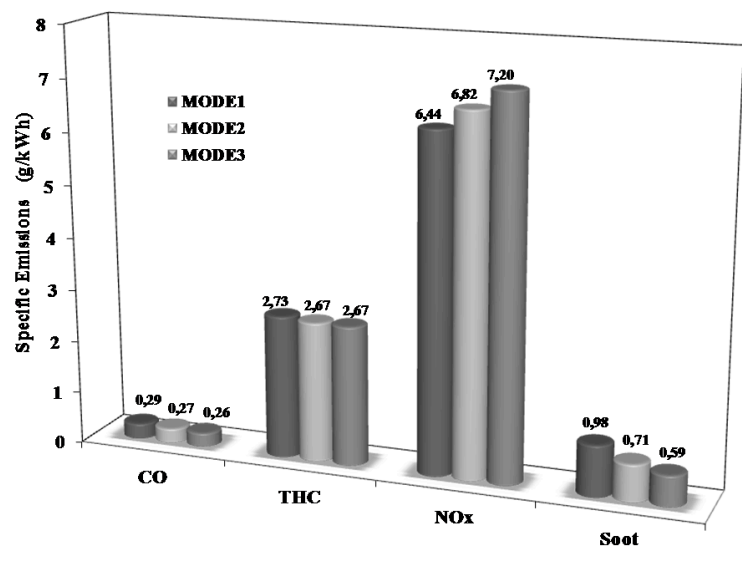

Figure 5. Specific emissions in modes.

The upcoming figures present the thermal and exergetic efficiency, exhaust and cooling exergy, uncounted loss exergy and exergy destruction that were calculated using the results of the engine test experiments and the results of the calculations. The thermal and exergetic efficiencies of Modes 1-3 are presented in Figure 6. The thermal efficiency of Mode 1 is the highest of all. In Mode 1, the thermal efficiency increases slightly compared to Mode 3. The increase of $\mathrm{NO}_{\mathrm{x}}$ means the increase of combustion efficiency. The results indicate that the increase of injection pressure reduces the brake work. The increase in the injection pressure caused a decrease in thermal efficiency. The increase of injection pressure by $17 \%$, caused decrease of thermal efficiency and power by $1 \%$. Drop size, injection velocity and injection rate are determined by injection pressure, injector nozzle hole size, nozzle type and geometry [32]. The increase of injection pressure promotes the decrease of droplet size, the decrease of ignition delay and shortens the duration of fuel injection event to combustion 
chamber. Higher injection pressure gives a finer droplet size, which reduces $\mathrm{HC}$ and particulate emissions but increases cylinder temperature and $\mathrm{NO}_{\mathrm{x}}$ emissions [33]. The decrease of droplet size promotes the shortening of ignition delay because faster evaporation which is triggered with the increased surface area. On the other hand, increase of injection pressure shortens the injection time for the same amount of fuel and increases the Rate of Heat Release Rate (RoHR) gradient. The in-cylinder pressure and temperature peak values and gradients increases because of this phenomenon. NO formation is strongly related with in-cylinder temperature exponentially. The increase of in-cylinder temperature increases the nitric oxide concentration [32,34]. The in-cylinder temperature and RoHR changing with injection pressure are given at Figures 2 and 3, respectively. The better mixture formation with the increase of injection pressure, shortening of ignition delay and increase of in-cylinder temperature decreases soot formation but because of increasing oxidation soot $\mathrm{CO}$ and $\mathrm{THC}$ decreases.

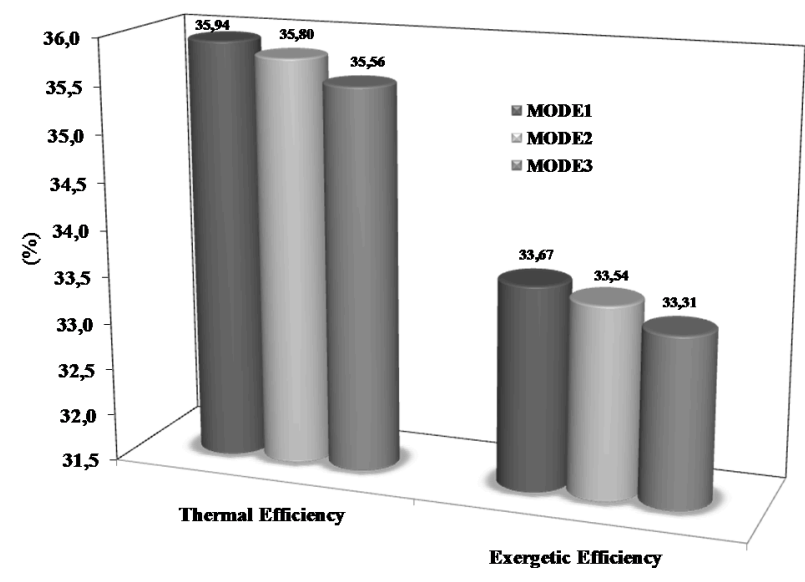

Figure 6. Change in the thermal and exergetic efficiency according to modes.

Although the mass of fuel injected per cycle in each mode was the same, the reduction in the brake work reduced the thermal and exergetic efficiencies.

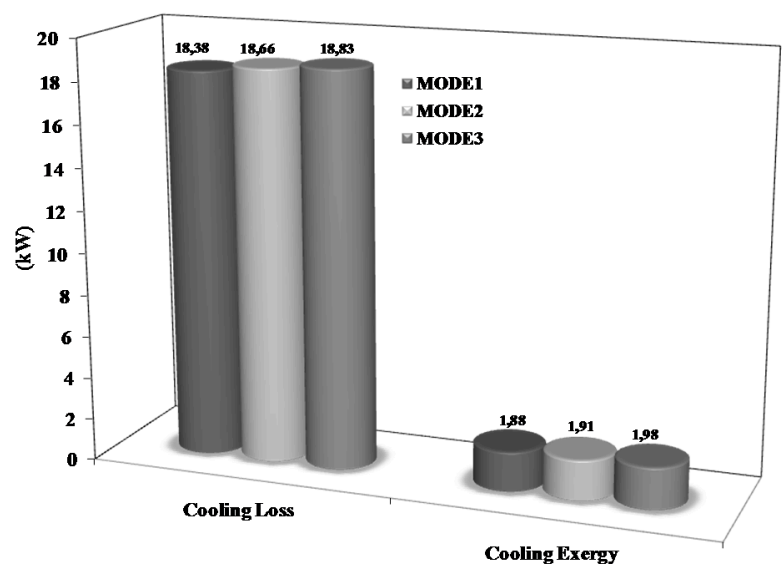

Figure 7. Change in the cooling loss and cooling exergy according to modes.

Change in cooling losses are given Figure 7. The results demonstrate that the cooling loss increases with injection pressure, which means that the cooling loss and the injection pressure were found to be directly proportional. The in-cylinder temperature is a significant parameter for the heat transfer from 
burned gases to cooling water. The heat transfer from burned gases to the cooling water increases with the in-cylinder temperature. Therefore the coolant water temperature rises. Although the heat transfer increases cooling water temperature, cooling exergy was reduced depending on the difference between cooling water and dead state temperatures.

The downstream exhaust heat loss in each mode is given in Figure 8; for comparison. The results show that the increase in injection pressure reduces exhaust heat loss. The reason for this is the increased cooling loss. The exhaust temperatures of modes are given in Table 6. The exhaust exergies of the modes have similar characteristics and they increase as the exhaust temperature increases. The energy analyses show that the exhaust gases hold weighty portion of work potential of fuel. In addition; the difference between exhaust gas and dead state temperature is caused by an increase of exhaust exergy. Exhaust loss is important; because of its big work potential and high temperature; compared with other losses.

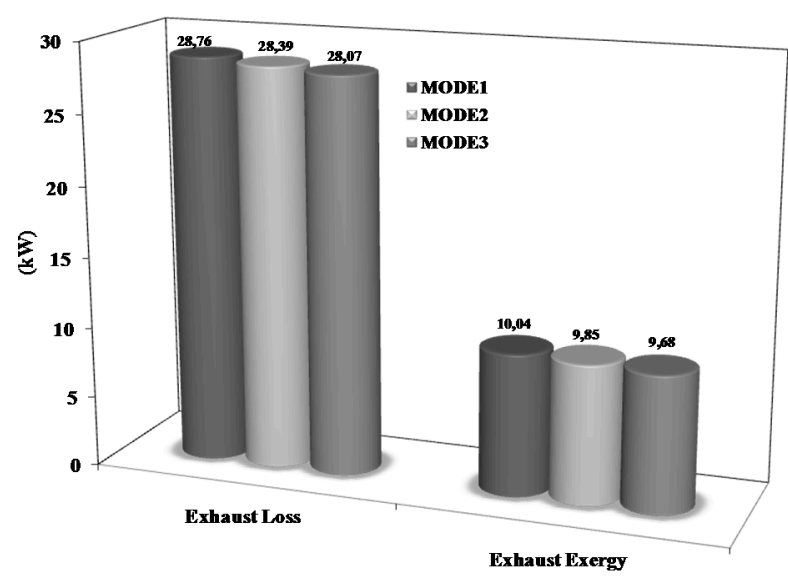

Figure 8. The change in the exhaust loss and exhaust exergy according to modes.

Table 6. Exhaust temperature measurement data.

\begin{tabular}{ccc}
\hline & Turbo Inlet & Turbo Outlet \\
\hline & $\mathrm{K}$ & $\mathrm{K}$ \\
MODE1 & 742.1 & 629.1 \\
MODE2 & 738.1 & 624.3 \\
MODE3 & 733.7 & 620.7 \\
\hline
\end{tabular}

According to the result, the difference in injection pressure did not affect the inter-cooling heat loss (Figure 9). The intake manifold pressure is hold held at constant level by the variable geometry turbocharger in different injection strategies. The air mass-flows through inter-cooler are the same for different injection pressures. The intercooler inlet and outlet pressures and temperatures, dead state conditions are the same in all modes. In addition and as a result, the heat-loss from inter-cooler and inter-cooling exergy were also same. The inter-cooling exergy is very low in all modes. This is the result of nearness of inter-cooler outlet temperature to the dead state temperature. 


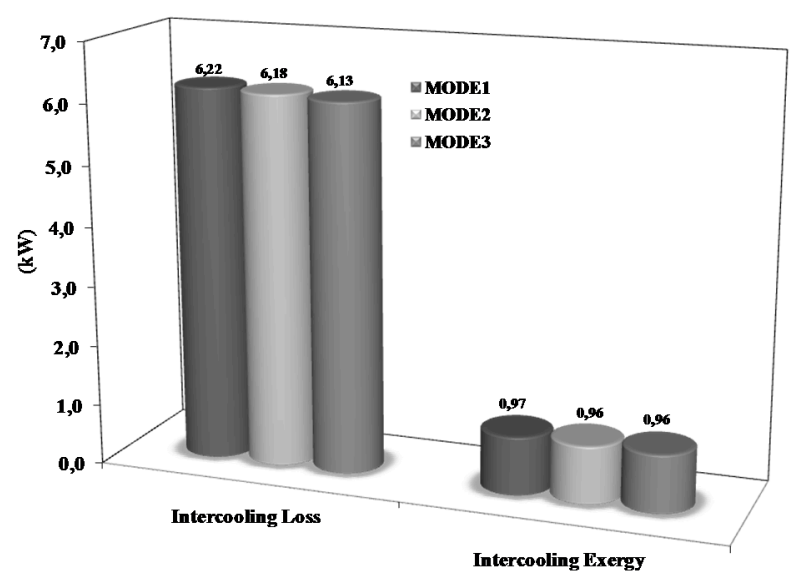

Figure 9. The change in the inter-cooling loss and inter-cooling exergy according to modes.

The uncounted heat losses of the modes are shown in Figure 10. Mode 3 has higher heat loss than others. It is difficult to calculate uncounted heat loss with using heat transfer equations due to the different heat transfer coefficients of the engine components and the complex engine block geometry. We calculated the uncounted heat loss by subtracting the sum of the brake work cooling heat loss, exhaust loss, and inter-cooling loss from the total heat energy of the injected fuel. Hence, the uncounted heat loss was calculated by subtracting the sum of the brake work, cooling heat loss, exhaust loss, and inter-cooling loss (calculated from the measurement results) from the total heat energy of the injected fuel.

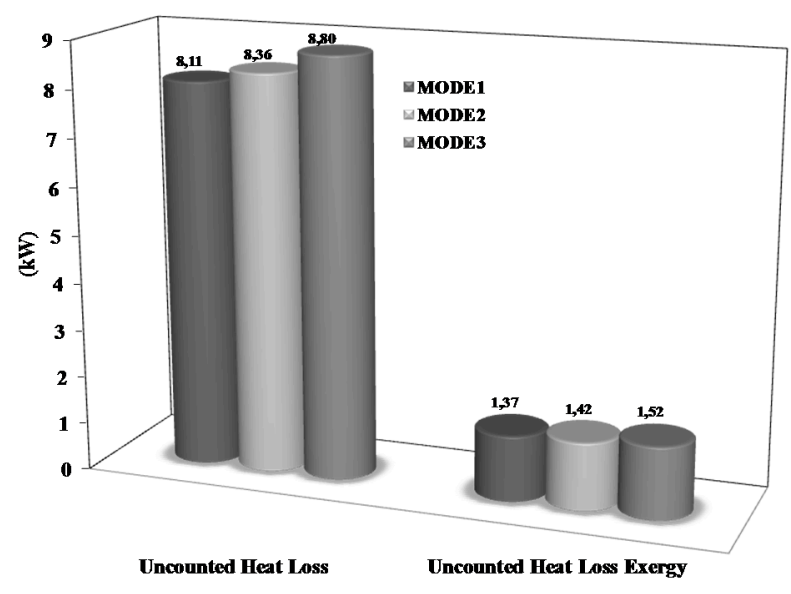

Figure 10. Change in the uncounted heat loss and uncounted heat loss exergy for modes.

The exergy distribution of Mode 1 is presented in Figure 11. In the Mode 1 injection strategy, the brake work, exergy and exergy destruction are $33.67 \%, 13.92 \%$ and $52.41 \%$, respectively.

The exergy distribution in Mode 1 is presented in Figure 11. In the Mode 1 injection strategy, the brake work, exergy and exergy destruction are $33.67 \%, 13.92 \%$ and $52.41 \%$, respectively. The exergy distribution in Mode 2 is presented in Figure 12. In Mode 2, the brake work, exergy and exergy destruction are $33.54 \%, 13.80 \%$ and $52.66 \%$, respectively. While the increase of injection pressure decreased the exhaust temperature and exergy, the cooling loss and cooling exergy were decreased. The total exergy was increased compared to Mode 1. 


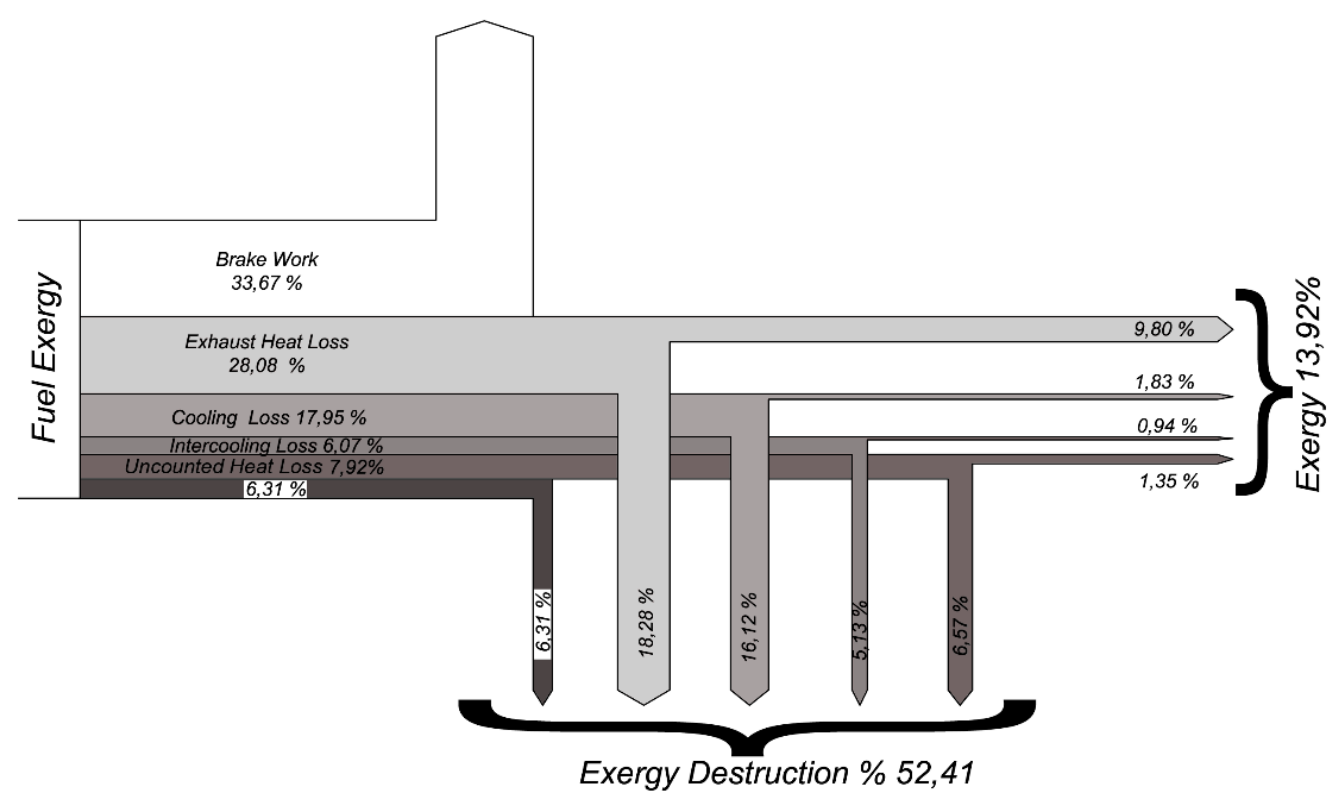

Figure 11. Sankey diagram for Mode 1.

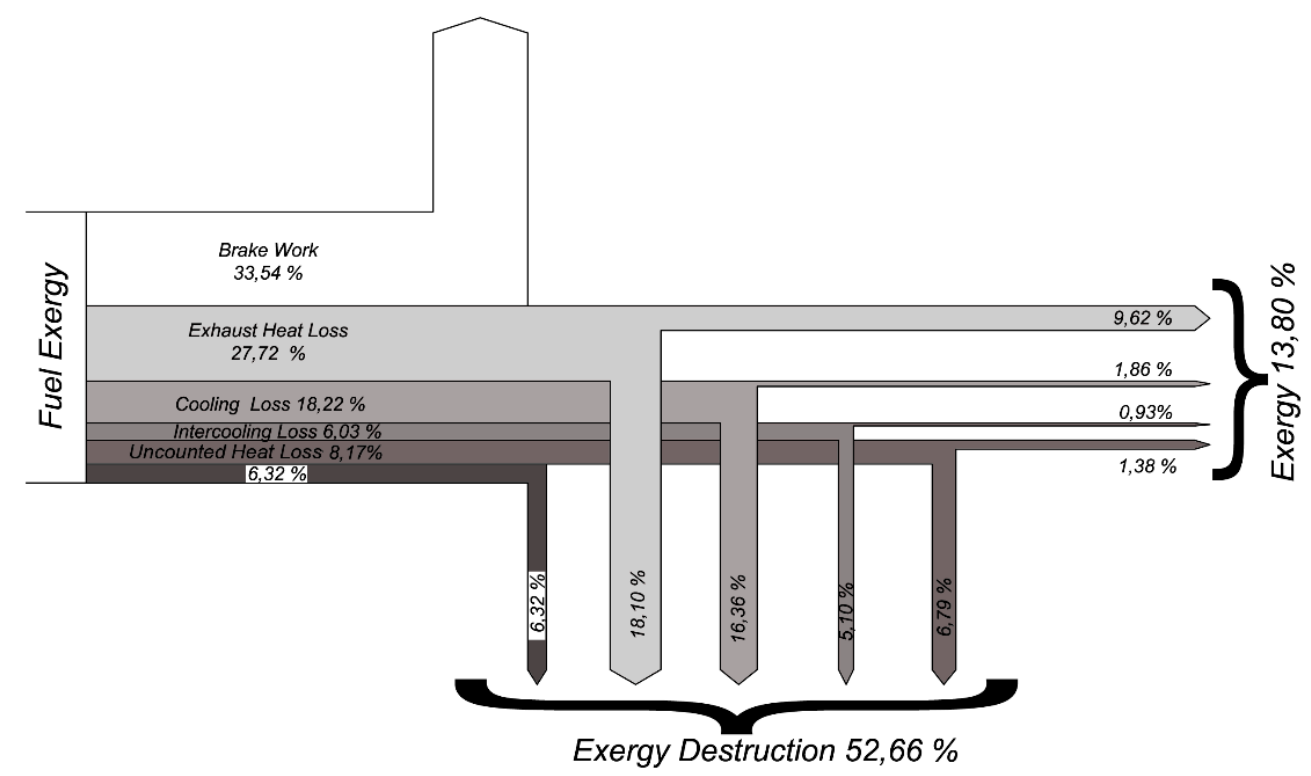

Figure 12. Sankey diagram for Mode 2.

The exergy distribution of Mode 3 is presented in Figure 13. In Mode 3, the brake work, exergy and exergy destruction are $33.31 \%, 13.80 \%$ and $52.89 \%$, respectively.

These results demonstrate that the increase of injection pressure decreases the exergy. This result arises primarily because the increase of injection pressure increases the cooling loss while reducing the exhaust temperature and exhaust loss. According to the second law of thermodynamics, the irreversibility of Mode 1 is lower than the irreversibilities of the other modes. It was found that the ratio of the exhaust exergy to the exhaust loss is $34.9 \%, 34.7 \%$ and $34.5 \%$; the ratio of the cooling exergy to the cooling loss is $10.2 \%, 10.2 \%$ and $10.5 \%$; the ratio of inter cooling exergy to inter cooling loss is $15.5 \%, 15.5 \%$ and $15.7 \%$; and the block heat exergy to the block heat loss is $16.9 \%, 16.9 \%$ and $15.7 \%$ respectively for Mode 1 , Mode 2 and Mode 3. These results demonstrate that the changing of the injection pressure has negligible effect on exergy to heat losses ratios. The brake work, exergy and 
exergy destruction of all modes are presented in Figure 14. The brake work values of Modes 1-3 are $33.67 \%, 33.54 \%$ and 33.31\%, respectively. The exergies of Modes $1-3$ are $13.92 \%, 13.80 \%$ and $13.80 \%$, respectively. The exergy destructions of Modes $1-3$ are $52.41 \%, 52.66 \%$ and $52.89 \%$, respectively. The results show that the heat fractions of the fuel are similar in all modes. The heat distributions are similar for each mode as brake work (1/3), exhaust loss (1/3), (including the intercooling loss) and cooling loss (1/3). These results demonstrate that the increase of injection pressure reduces the brake work and the exergy.

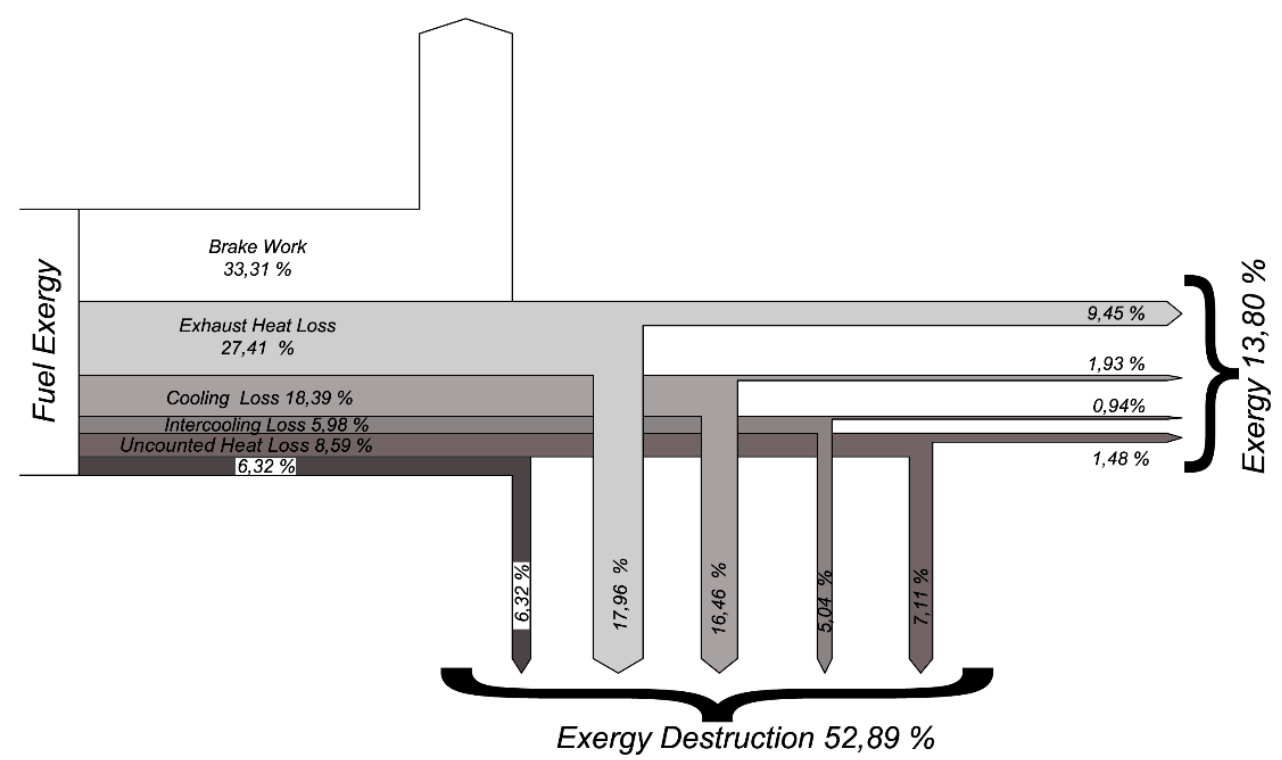

Figure 13. Sankey diagram for Mode 3.

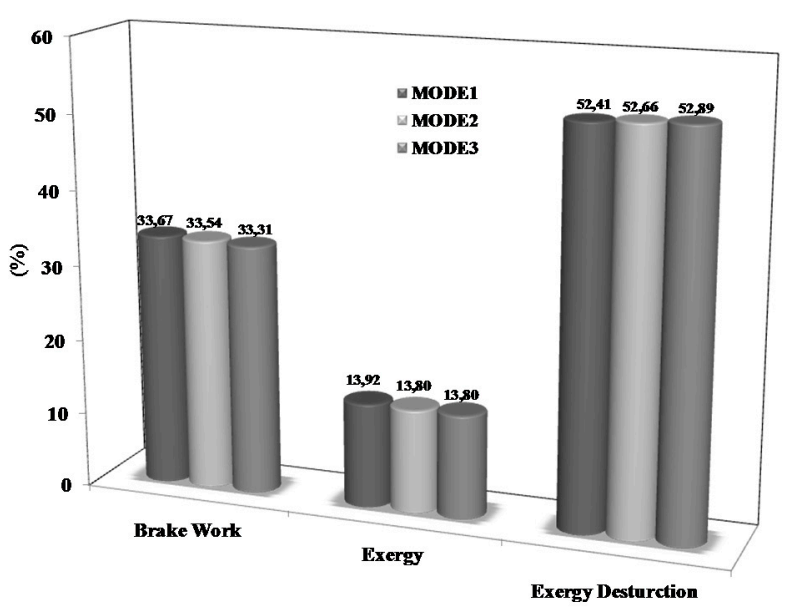

Figure 14. Brake Work, Exergy and Exergy Destruction of Modes.

\section{Conclusions}

In this study, the effect of injection pressure on combustion, thermal and exergetic efficiencies are studied in terms of the second law of thermodynamics. The results obtained showed that as the injection pressure increases, the indicated power increases because of the increased combustion efficiency, although the brake power decreases at the same time. These results showed that, the power 
required of an injection pump to pressurize the fuel for a Diesel engine is greater than the increased engine power associated with an increased in the injection pressure. Increasing the injection pressure reduces soot emissions with little decrease in the brake power. This operating condition occurs when the smoke value exceeds the value indicated in the emission regulations. In addition, the exergy decreased slightly when the injection pressure increased. Increasing the injection pressure decreased both the thermal and exergetic efficiencies. The injection pressure is inversely proportional to the thermal and exergetic efficiencies. Exergy destruction is $\sim 6 \%$ independent of the injection pressure. Injection pressure has a significant effect on thermal and exergetic efficiencies. The study showed that it is possible to increase exergetic efficiency of a CI engine by adjusting the injection pressure.

However, in an internal combustion engine, the priority problem is to provide the emission levels identified by international standards. Therefore, exergetic efficiency is not the first goal for an engine designer. A low difference between source and dead state temperatures causes low exergetic efficiency. Therefore, exergetic efficiency of total coolant loss is less than exhaust exergetic efficiency. The exhaust exergy is important due to the high temperature of exhaust gases. This means that exhaust exergy and exergy efficiency are higher than others. The results showed that a decrease in injection pressure increases exhaust exergy by decreasing cooling loss. Using the energy of exhaust gases, the turbo charger converts the thermal work to mechanical work. The increase of exergy destruction was found to be a factor that limits the injection pressure. The second-law methodology demonstrated in this paper can be beneficial in the design, development and performance analysis of similar engine systems.

\section{Acknowledgments}

The authors would like to thank the Ford Otosan A.S. for its support.

\section{Nomenclature}

$\begin{array}{ll}\text { Ex } & \text { Exergy }(\mathrm{kW}) \\ \dot{Q} & \text { Heat }(\mathrm{kW}) \\ \dot{m} & \text { Mass flow rate }(\mathrm{kg} / \mathrm{h}) \\ \dot{W} & \text { Work }(\mathrm{kW}) \\ \mathrm{CA} & \text { Crank angle }\left({ }^{\circ}\right) \\ \mathrm{CLD} & \text { Chemiluminescence detector } \\ \bar{c} p & \text { Specific heat }(\mathrm{kJ} / \mathrm{kmol} \mathrm{K}) \\ \mathrm{e} & \text { Specific exergy }(\mathrm{kJ} / \mathrm{kg}) \\ \bar{e} & \text { Specific molar exergy }(\mathrm{kJ} / \mathrm{kmol}) \\ \mathrm{ECU} & \text { Electronic control unit } \\ \mathrm{EGR} & \text { Exhaust gas recirculation } \\ \mathrm{FID} & \text { Flame ionization detector } \\ \mathrm{RoHR} & \text { Rate of Heat Release } \\ \mathrm{h} & \text { Specific enthalpy }(\mathrm{kJ} / \mathrm{kg}) \\ \mathrm{LHV} & \text { Low heat value }(\mathrm{kJ} / \mathrm{kg}) \\ \mathrm{MIFQ} & \text { Main-injected fuel quantity } \\ \mathrm{n} & \text { Molar number } \\ \mathrm{NDIR} & \text { Non-dispersive infrared detector } \\ \mathrm{p} & \text { Pressure }(\text { Pa) } \\ \mathrm{PIFQ} & \text { Pre-injected fuel quantity } \\ \mathrm{PMD} & \text { Paramagnetic detector } \\ \mathrm{Ru} & \text { Universal gas consist }(\mathrm{kJ} / \mathrm{kg} \mathrm{K})\end{array}$


$\mathrm{S}$

$\bar{S}$

$\mathrm{T}$

TDC

ATDC

TIFQ

VGT

$\mathrm{y}$

Greek letters

$\alpha$
$\eta$
$\varepsilon$
$\lambda$

\section{Subscripts}

$\mathrm{T}$

th

f

0

exh

in

out

a

eff

$\mathrm{u}$

dest

\section{Superscript}

e

ic

$\mathrm{ch}$

cw
Specific entropy $(\mathrm{kJ} / \mathrm{kg} \mathrm{K})$

Specific molar entropy ( $\mathrm{kJ} / \mathrm{kmol} \mathrm{K}$ )

Temperature (K)

Top dead center

After top dead center

Total injected fuel quantity

Variable geometry turbine

Molar ratio (\%)

Crank angle

Efficiency

Exergetic efficiency

Excess air ratio

Thermal

Thermomechanic

Fuel

Dead state

Exhaust

Inlet

Outlet

Air

Effective

uncounted

Destruction

Source

Environment

Intercooler

Chemical

Cooling water

\section{Conflicts of Interest}

The authors declare no conflict of interest.

\section{References}

1. Rosen, M.A. Using exergy to correlate energy research investments and efficiencies: Concept and case studies. Entropy 2013, 15, 262-286.

2. Dincer, I. Thermodynamics, exergy and environmental impact. Energy Sour. 2000, 22, 723-732.

3. Dincer, I. Special issue on entropy generation in thermal systems and processes. Entropy 2003, 5, doi:10.3390/e5050357.

4. Dincer, I.; Cengel, Y.A. Energy, entropy and exergy concepts and their roles in thermal engineering. Entropy 2001, 3, 116-149.

5. Açıkkalp, E.; Aras, H.; Hepbasli, A. Advanced exergy analysis of a tri-generation system with a diesel-gas engine operating in a refrigerator plant building. Energy Build. 2014, 80, 268-275.

6. Santo, D.B.E. Energy and exergy efficiency of a building internal combustion engine tri-generation system under two different operational strategies. Energy Build. 2012, 53, 28-38. 
7. Ehyaeia, M.A.; Ahmadib, P.; Atabic, F.; Heibatic, M.R.; Khorshidvand, M. Feasibility study of applying internal combustion engines in residential buildings by exergy, economic and environmental analysis. Energy Build. 2012, 55, 405-413.

8. Chintala, V.; Subramanian, K.A. Assessment of maximum available work of a hydrogen fueled compression ignition engine using exergy analysis. Energy 2014, 67, 162-175.

9. López, I.; Quintana, C.E.; Ruiz, J.J.; Cruz-Peragón, F.; Dorado, M.P. Effect of the use of olive-pomace oil biodiesel/diesel fuel blends in a compression ignition engine: Preliminary exergy analysis. Energy Convers. Manag. 2014, 85, 227-233.

10. Azoumah, Y.; Blin, J.; Daho, T. Exergy efficiency applied for the performance optimization of a direct injection compression ignition (CI) engine using biofuels. Renew. Energy 2009, 34, 1494-1500.

11. Calıskan, H.; Tat, M.E.; Hepbasli, A. Performance assessment of an internal combustion engine at varying dead (reference) state temperatures. Appl. Therm. Eng. 2009, 29, 3431-3436.

12. Nieminen, J.; Dincer, I. Comparative exergy analyses of gasoline and hydrogen fuelled ICEs. Int. J. Hydr. Energy 2010, 35, 5124-5132.

13. Waller, M.G.; Williams, E.D.; Matteson, S.W.; Trabold, T.A. Current and theoretical maximum well-to-wheels exergy efficiency of options to power vehicles with natural gas. Appl. Energy 2014, 127, 55-63.

14. Jafarmadar, S. Exergy analysis of hydrogen/diesel combustion in a dual fuel engine using three-dimensional model. Int. J. Hydr. Energy 2014, 39, 9505-9514.

15. Jafarmadar, S. Multidimensional modeling of the effect of EGR (exhaust gas recirculation) mass fraction on exergy terms in an indirect injection diesel engine. Energy 2014, 66, 305-313.

16. Jafarmadar, S. Three-dimensional modeling and exergy analysis in Combustion Chambers of an indirect injection diesel engine. Fuel 2013, 107, 439-447.

17. Saxena, S.; Shah, N.; Bedoya, I.; Phadke, A. Understanding optimal engine operating strategies for gasoline-fueled HCCI engines using crank-angle resolved exergy analysis. Appl. Energy 2014, $114,155-163$.

18. Sezer, I.; Bilgin, A. Effects of charge properties on exergy balance in spark ignition engines. Fuel 2013, 112, 523-530.

19. Fu, J.; Liu, J.; Feng, R.; Yang, Y.; Wang, L.; Wang, Y. Energy and exergy analysis on gasoline engine based on mapping characteristics experiment. Appl. Energy 2013, 102, 622-630.

20. Ghazikhani, M.; Hatami, M.; Ganji, D.D.; Gorji-Bandpy, M.; Behravan, A.; Shahi, G. Exergy recovery from the exhaust cooling in a DI diesel engine for BSFC reduction purposes. Energy 2014, 65, 44-51.

21. Nemati, A.; Fathi, V.; Barzegar, R.; Khalilarya, S. Numerical investigation of the effect of injection timing under various equivalence ratios on energy and exergy terms in a direct injection SI hydrogen fueled engine. Int. J. Hydr. Energy 2013, 38, 1189-1199.

22. Zheng, J.; Caton, J.A. Second law analysis of a low temperature combustion diesel engine: Effect of injection timing and exhaust gas recirculation. Energy 2012, 38, 78-84.

23. Da Costa, R.Y.J.; de Lima, A.G.B.; Filho, C.R.B.; de Araujo Lima, L. Energetic and exergetic analyses of a dual-fuel diesel engine. Renew. Sustain. Energy Rev. 2012, 16, 4651-4660. 
24. Karra, P.; Kong, S. Diesel emission characteristics using high injection pressure with converging nozzles in a medium-duty engine. SAE Int. J. Fuels Lubr. 2008, 1, 578-592.

25. Ozkan, M.; Ozkan, D.B.; Ozener, O.; Y1lmaz, H. Experimental study on energy and exergy analyses of a diesel engine performed with multiple injection strategies: Effect of pre-injection timing. Appl. Ther. Eng. 2013, 53, 21-30.

26. Cengel, Y.A.; Boles, M.A. Thermodynamics: An Engineering Approach, 5th ed.; McGraw Hill: Boston, MA, USA, 2006.

27. Kotas, T.J. The Exergy Method of Thermal Plant Analysis; Krieger Publishing Company: Malabar, FL, USA 1995.

28. Canakci, M.; Hosoz, M. Energy and exergy analyses of a diesel engine fuelled with various biodiesels. Energy Sour. B 2006, 11, 379-394.

29. Chmela, F.; Orthaber, G.; Schuster, W. Die Vorausberechnung des Brennverlaufs von Dieselmotoren mit direkter Einspritzung auf der Basis des Einspritzverlaufs. Motortechnische Zeitschrift 1988, 59, 484-492.

30. Chmela, F.; Orthaber, G. Rate of Heat Release Prediction for Direct Injection Diesel Engines Based on Purely Mixing Controlled Combustion; SAE International: Warrendale, PA, USA, 1999. doi:10.4271/1999-01-0186.

31. Ozener, O. Optimisation of pilot injection strategies in diesel engines from the perspective of performance and emissons. Ph.D. Thesis, Yildiz Technical University: İstanbul, Turkey, 2013.

32. Heywood, J.B. Internal Combustion Engines Fundementals; Mc Graw Hill: New York, NY, USA, 1989.

33. Pulkrabek, W.W. Engineering Fundamentals of the Internal Combustion Engine, 2nd ed.; Prentice Hall: Upper Saddle River, NJ, USA, 2003.

34. Warnatz, J.; Maas, U.; Dibble, R.W. Combustion: Physical and Chemical Fundamentals, Modeling and Simulation, Experiments, Pollutant Formation, 4th ed.; Springer: Berlin/Heidelberg, Germany, 2006.

(C) 2015 by the authors; licensee MDPI, Basel, Switzerland. This article is an open access article distributed under the terms and conditions of the Creative Commons Attribution license (http://creativecommons.org/licenses/by/4.0/). 